with chronic hepatitis $\mathrm{B}(\mathrm{CH}-\mathrm{B})$. Whether pre-treatment $\mathrm{HBsAg}$ plasma levels correlate with liver relaxed circular (RC) HBV DNA and covalently closed circular (ccc) DNA is controversial. To date, no information is available on $\mathrm{HBsAg}$ plasma level behaviour and response to treatment prediction in tolerant patients with infancy-acquired CH-B treated with lamivudine (LAM) and IFN.

Aim To investigate whether $\mathrm{HBsAg}$ plasma levels predict response to LAM + IFN treatment in tolerant children with infancy-acquired $\mathrm{CH}-\mathrm{B}$, and to determine their association with plasma HBV DNA levels during treatment and with pre-treatment liver RC HBV DNA and cccDNA.

Method Patients: 23 children (8 males, median age 10.2 yrs) with infancy-acquired $\mathrm{CH}-\mathrm{B}$ (all $\mathrm{HBeAg}$ positive), treated for 52 weeks [lead-in LAM (3 mg/kg/d) for 9 weeks; LAM plus IFN- $\alpha\left(5 \mathrm{MU} / \mathrm{m}^{2}\right.$ TIW) from week 9 for 44 weeks], were divided according to treatment response: 5 responders $(\mathrm{R}=$ anti-HBs seroconversion) and 18 non-responders (NR).

Methods: Plasma HBsAg and HBV DNA levels were measured before (treatment week 0, TW0), during (TW9, TW28, TW52) and after (follow-up week, FUW24) therapy by Abbott ARCHTECT_ assay and real-time TaqMan PCR [both $\log _{10} \mathrm{IU} / \mathrm{ml}$. Baseline liver RC HBV DNA and cccDNA was quantified by real-time TaqMan PCR [copies/ng genomic DNA]. Results are presented as median.

Results Baseline HBsAg levels were lower in R than NR (4.36 vs 4.74, $p=0.02)$, but similar in R and NR at the end of LAM lead-in therapy (TW9) (4.34 vs 4.66, $\mathrm{p}=0.1$ ). During IFN add-on therapy, at TW28 (2.34 vs 4.33) and TW52 (0 vs 4.08) levels were markedly lower in R than NR, the difference persisting at FUW24 (0 vs 4.51) $(\mathrm{p}<0.01$ for all). Plasma HBV DNA levels were similar at baseline in $\mathrm{R}$ and NR (8.94 vs 8.98), but decreased significantly in R compared to NR at TW9 (4.91 vs 5.48), TW28 (3.42 vs 4.39), TW52 (1.57 vs 4.07) and FUW24 (0.27 vs 7.75) ( $p<0.01$ for all). There was a strong positive correlation between plasma HBsAg and HBV DNA levels at TW28 $(\mathrm{r}=0.6, \mathrm{p}<0.01)$ and TW52 $(\mathrm{r}=0.64, \mathrm{p}<0.01)$. Baseline liver RC HBV DNA (43800 vs 52300 copies/ng genomic DNA) and cccDNA (41 vs 49 copies/ng genomic DNA) were similar in R and $\mathrm{NR}$, with no correlation between liver RC HBV DNA or cccDNA and baseline HBsAg.

Conclusion Lower baseline HBsAg plasma levels and a sharp decrease of plasma HBV DNA levels at TW9 (LAM lead-in) followed by declining plasma HBsAg levels from TW28 (IFN add-on) heralds $\mathrm{HBsAg}$ clearance and response to treatment in tolerant children with $\mathrm{CH}-\mathrm{B}$.

\section{P67 SWITCH TO OTHER NUCLEOS(T)IDE ANALOGUES THERAPY IN CHRONIC HEPATITIS B COHORT ON LONG-TERM DE- NOVO COMBINATION THERAPY WITH LAMIVUDINE PLUS ADEFOVIR: EFFICACY AND SAFETY}

doi:10.1136/gutjnl-2011-300857a.67

I Carey, A Mendes, D Joshi, M Bruce, S Knighton, A Scalori, S Hughes, M Al-Freah, A Suddle, P M Harrison, ${ }^{1} \mathrm{~K}$ Agarwal. ${ }^{1}$ Institute of Liver Studies, King's College Hospital NHS Foundation Trust

Introduction Long-term de-novo combination therapy with lamivudine (LAM) $100 \mathrm{mg} / \mathrm{d}+$ adefovir (ADV) $10 \mathrm{mg} / \mathrm{d}$ is highly efficient, with no/minimal drug resistance and good safety profile. Tenofovir (TDF) $245 \mathrm{mg} / \mathrm{d}$ or entecavir (ETV) $0.5 \mathrm{mg} / \mathrm{d}$ are highly efficacious antivirals with high resistance barrier and provide alternative to LAM + ADV combination therapy.

Aim We aimed to investigate the virological and serological responses and renal/bone safety after switch from LAM + ADV to other antiviral drugs.

Method Patients: Nucleos(t)ide analogues naive $192 \mathrm{CHB}$ patients (78\% males, median age $40 \mathrm{y}, 35 \% \mathrm{HBeAg}+, 34 \%$ cirrhosis) were treated with de-novo LAM+ADV at a single-centre practice (median 36 months). 149 patients from this cohort were switched to other nucleos(t)ide analogues therapy: 101 (68\%) to TDF monotherapy, 28 $(19 \%)$ to TDF plus emctritabine, 14 (9\%) patients to ETV monotherapy and $6(4 \%)$ patients to other antivirals. Median duration of therapy after switch was 14 months. Reasons for the switch were following: 33 patients slow-response/non-response, 14 had drug-related renal impairment, 5 due to pregnancy, 2 after liver transplantation and 95 patients were switched for other reasons.

Methods Number of patients achieved HBeAg seroconversion and complete virological response (CR) (HBV DNA $<12 \mathrm{IU} / \mathrm{ml}$ ) was compared (LAM+ADV vs. switch). Differences between serum levels of HBV DNA, creatinine and phosphate and estimated glomerular filtration rates (eGFR) were assessed at each time-point and compared between groups and with baseline. HBV genotypic resistance was tested in all patients with suboptimal response by direct sequencing.

Results Baseline HBV DNA was significantly higher in LAM+ADV vs switch group (median $\log _{10} 4.6$ vs $0.89 \mathrm{IU} / \mathrm{ml}, \mathrm{p}<0.01$ ), there was higher proportion of responses after switch than at time of switch and when compared to LAM+ADV (switch baseline $76 \%$ vs $\mathrm{m} 3$ switch $91 \%, p=0.02$ vs m3 LAM+ADV 48\%, $p<0.01$ ). On LAM $+\mathrm{ADV}$ therapy 14 patients achieved $\mathrm{HBeAg}$ and 3 patients $\mathrm{HBsAg}$ seroconversion and additional 3 patients and 1 patient seroconverted $\mathrm{HBeAg}$ and $\mathrm{HBsAg}$ after switch. No viral mutations associated with drug resistance were detected in LAM+ADV and after switch. There were no significant differences in serum creatinine or eGFR between groups at each time-point, but comparing to baseline there was significant decrease in eGFR from M18 onwards in LAM+ADV group $(82.2 \mathrm{vs} 76.2 \mathrm{ml} / \mathrm{s}, \mathrm{p}=0.04)$. The proportion of patients with eGFR $<60 \mathrm{ml} / \mathrm{s}$ did not changed during LAM+ADV therapy and after switch. Serum phosphate levels $[\mathrm{mmol} / \mathrm{l}]$ fell on therapy in LAM+ADV from M12 (M12: -0.04, M18: -0.06 and M24: -0.05 ) and remained unchanged after switch.

Conclusion Switch to other nucleos(t)ide analogues from long-term de-novo combination LAM+ADV therapy was efficient and was not associated with impact on renal/bone safety.

\section{P68 IS IT WORTH TESTING UNSTABLE DRUG USERS FOR HEPATITIS C?}

doi:10.1136/gutjnl-2011-300857a.68

\section{B P Stephens. Ninewells Hospital, Dundee}

Introduction Within the UK the main source of hepatitis $\mathrm{C}$ virus (HCV) infection is injecting drug use however, diagnosing $\mathrm{HCV}$ in chaotic drug users has often proved challenging, particularly if venous access is a problem.

Aim To evaluate the introduction of HCV dry blood spot testing (DBST) by staff working in addiction services and to determine if individuals who agreed to testing, returned for their results and accessed appropriate follow-up into either drug or HCV treatment. Method The study was carried out over an 18-month period between 2009 and 2010. Testing for HCV was offered to individuals who accessed addiction services during this period. A follow-up appointment was issued for 2 weeks after testing. The numbers tested were monitored and data were collected on follow-up appointments attended.

Results During the study, 661 tests were carried out using the DBST method. 479 (72.5\%) within needle exchange services and 182 $(27.5 \%)$ from drug treatment services. $439(66 \%)$ were male, and the age range was 18 to 51 years with a median age of 32 years. 608 $(91.3 \%)$ individuals returned for the results of their test and 186 (28\%) of the 661 tests were HCV antibody positive. Follow-up bloods were offered to all positive patients. Of the 147 (79\%) who 